\title{
The Connotation, Necessity and Practical Strategies of Children's Dietary Education
}

\author{
Jiayi Zhang \\ School of Primary Education \\ Linyi University \\ Fei County, Shandong Province 273400
}

\begin{abstract}
Dietary education” means education of dietary behaviors. The early childhood is the best time to cultivate the balanced diet habits. With the early childhood education as a starting point, dietary education helps children to develop the recipe memory of balanced diets by means of dietary education into the classroom and homeland construction starting from the implementation of "cultivation education"; starting with "compensatory education", it also corrects bad dietary behaviors of children who are overweight or underweight in time and lays a good foundation for people's healthy life by establishing health records, assessing children's nutritional status.
\end{abstract}

Keywords—dietary education connotation; necessity; strategies

\section{INTRODUCTION}

China's dietary culture has a long history of five thousand years. However, people became able to stuff themselves from the era of starvation just a few decades ago. In the daily life, people tend to apply their dietary experience in the era of starvation to the modern life. Faced with various kinds of modern food, they are all at sea when they make choices simply based on their sided life experience. People have own preferences and are fastidious about food. Some people eat and drink too much and have food containing additive excessively, which damage their health (such as overweight, hypertension, diabetes and children's precocious puberty). In order to change this situation, people began to seek solutions to this problem. They thought about education and decided to start from children. Hence, they began to explore another important educational content of nursery schools, which was "dietary culture”.

\section{CONNOTATION OF DIETARY EDUCATION}

"Dietary education" mainly refers to education of dietary behaviors, including education of dietary concept, knowledge of dietary and nutrition, food safety and knowledge of Nutrition and Hygiene. It is an education which develops people's abilities of selecting food scientifically and having a healthy life. [1] It is a harmonious education which teaches people to treat nature kindly, to obtain less from nature as well as to protect the environment. It is an education of our traditional food culture and an education which helps people develop good eating habits through various forms. Its basic idea is: to provide children with education of food-related knowledge from early childhood and also to extend this kind of dietary education to the cultivation of artistic imagination and outlook on life. No matter who you are, you can develop good eating habits happily in a simple way and keep it for life. Therefore, dietary education is not only known as nutrition knowledge popularization, but to make people form a strong impression of healthy delicious food by eating and turn good eating habits as well as healthy recipes and eating mode into their habits, consciously reflecting in everyday life. [2] This interesting "dietary education" can be accepted by children easily. So, it is rapidly promoted in the families and early childhood institutions.

\section{THE NECESSITY OF STRENGTHENING CHILDREN'S DIETARY EDUCATION}

\section{A. Early childhood is the best time for food and dietary education}

The brain development is the most important thing within one or two years from the fetus to the birth. Along with the increasing weight, the number of brain cells will increase to 12 14 billion in one year [3]. After the birth, the synapses connected by the nerve cells begin to take shape and they will cover $60 \sim 80 \%$ of the neuronal surface area. At the age of $3 \sim 4$, children will basically complete the nerve myelination. The myelin sheath of nerve fibers can make the neurons deliver information accurately. Children basically form the neural basis of learning and memorization. However, the neural activity process is still in an unstable state. The excitatory process prevails. The conditioned reflex can be established fast, faded fast and recovered fast as well. It shows that children's development of the second signal system is imperfect while the first signal system prevails. Children have relatively strong visual image thinking abilities and they are good at imitating while their abstract thinking abilities are relatively poor. They accept demonstration and other visual teaching methods easily [3]. During this period, people's sense organs (hearing, sight, taste, touch) are at the most sensitive stage. It is not only the most important education period but also the best period for the development of balanced diet habits. Whether the feeding modes and food preferences are correct or not, once formed, they will last for life and it is difficult to change.

\section{B. The industrialization, commercialization, safety of food call for dietary education}

With the highly developed food industrialization and commercialization, the food trademarks are designed by using 
the modern industrial technology in the marketing competitions. Too much industrial additives are used in the food, making the food safety issues more prominent. Many children and adolescents cannot resist the temptation of food looks, color, and taste. They are often captured by many "new types of junk food". Overweight and allergic constitution become serious threats and do harm to the health of the younger generation. The study shows that chronic diseases like hypertension, high cholesterol and diabetes which adults used to suffer from now have threaten the health of children and adolescents. They are called as "children's adult chronic diseases". The modern agriculture uses pesticides and fertilizers excessively with multiplied input of mechanical power, destroying nature increasingly. Soil compaction, water shortage and lack of energy all bring crises to the food safety, seriously affecting people's sustainable development. Thus, the implementation of food safety education and harmonious education between Man and Nature from early childhood has the far-reaching strategic significance.

\section{China's food cultural heritage needs dietary education}

The agricultural production structure and markets concern people's health and the country's fate. In order to safeguard national interests and enhance national cohesion, all countries and ethnic groups attach great importance to the nation's cultural heritage, especially the food cultural heritage. China's food culture is rooted in the agricultural economy. There's an obvious border of main and subsidiary food in the dietary structure, which follow the dialectical outlook that medicine and food share the same origin. In Inner Canon of Huangdi - Plan Questions, there is a balanced dietary concept believing that "poisonous drugs can be used as medical treatments. Food crops are the main nutrition resources. Fruits are helpful. Prime Five (horses, camels, cows, sheep, goats) are beneficial. Vegetables are essential. If these things are combined correctly, people can boost the energy by eating them". Dietary should pay attention on "time, season and amount”. It needs to be healthy, simple and ordinary. Influenced by Confucianism, Taoism and Buddhism, it focuses on the food's color, smell, taste, shape and device, with the taste as the core and the nutrition as purpose. The cooking methods are elaborate and complicated. There are various kinds of cuisine and schools, caring about love eating, friendly eating, fine eating, nourishing eating and polite eating. It is China's tradition to advocate and observe etiquette as well as focus on education for thousands of years. It is performed throughout the course of dietary activities, which constitutes the logical starting point of Chinese food culture. [5] Hence, we should show our food culture to children in early childhood education so that they can realize that food comes from agriculture while our land, water and energy are far from inexhaustible but hard earned at an early age. Only by establishing the new "etiquette" trend of hardworking and simplicity, food saving, reasonable diets, respect for teachers and elders as well as morality can achieve the harmony and unity of man and nature, man and the environment.

\section{THE PRACTICAL STRATEGIES OF CHILDREN'S DIETARY} EDUCATION

\section{A. Cultivate children's recipe memory of a balanced diet from "cultivation education"}

Cultivation education includes the guidance of proper behaviors. It is an education to help children develop good habits. Habit is the product of cultivation education. It is often originated from little things which seem to be casual but they contain tremendous energy enough to change the destiny of mankind. Through cultivation education, children are supposed to turn food's stimuli to taste into happy memories and to combine with recipes of the balanced diet. The combination of happy memories, taste experience and healthy food can develop children's balanced diet habits

1) Dietary education into the classroom is children's main source of correct dietary patterns

Classroom teaching shall be the main front of the contact between teachers and students as well as children's learning. It is an important way for teachers to correct children's bad behaviors and help them form good learning habits. It is also the main place for teachers to teach children nutrition knowledge and dietary patterns consciously. Currently, in the absence of unified textbooks, teachers should pay attention to the persistence and flexibility of daily dietary. Teachers can prepare teaching plans, lesson plans combined with diet recipes according to the season features. Through various forms of creativity, teacher can help children remember knowledge of food and nutrition visibly or invisibly. For example, learn by using Doman Flash Cards, let children enjoy the comics, listen to stories, act out stories, food DIY, etc. Try to meet children's psychological adventures in colors and patterns. Cultivate children's preferences to different foods and develop balanced dietary habits including love of hardworking and thrift by making children experience interesting teaching which is new and creative.

2) Home construction is an important way to cultivate children's balanced dietary habits

Actually, during the growth process, every person will develop a special preference to food, which means different tastes. Sour, sweet, bitter, spicy, salty, fishy differ from each other. Most of these tastes are related to environmental impacts, especially to the influences of families and parents. Thus, in the development of children's nutrition teaching plans, teachers should also consider the periodic training for parents so that parents can accept the universal education of some nutritional knowledge, including medicine, nutrition basics knowledge, the impact of nutrition on children's mental development, catering knowledge, nutrition prevention of children's common diseases. Parents are supposed to induce children not to have partial eclipses and to form healthy eating habits correctly. When developing the weekly recipes, teachers should deliver the recipe information to parents promptly. Teachers should enable children to combine the food learned in class with the eating practice at school and at home while teaching nutrition knowledge. With good examples of teachers or parents eating with children, children will imitate naturally. The subtle penetration can make children have healthy and delicious memories of science diets by enjoying the eating practice. 
Through constant strengthening and integration, children will turn the healthy recipes and feeding modes into own habits so that they can keep the correct eating habits for life.

3) Create a relaxed and harmonious dining environment, build a pleasant dining atmosphere.

The merits of kindergartens' dining environment will directly affect the quality of children's diets. The dining environment includes physical and psychological environment: physical environment means that facilities should be placed properly with adequate lighting, clean air circulation and suitable temperature. The dining tables and dinnerware should be clean and beautiful. The sizes should be appropriate. The canteen should be clean and elegant with all items neatly placed. Psychological environment means harmonious atmosphere, including teachers' attitudes, words and actions when they organize meals. Teachers should not force children to eat. No physical punishment and criticism. Try to create opportunities for children to serve themselves, choose seats freely and have meals with friends. Psychological environment also includes teachers' goodwill showed to food, so that children feel happy and eat joyfully. Among all environmental factors constituting eating practice, teachers' words and attitudes are the most important, followed by influences of children's behaviors, moods and eating habits. Therefore, in the dining process, teachers should communicate with students, integrating knowledge education with emotional communication, behavior training. Some beautiful and relaxing music can be played to promote children's appetite. Noises, congestion, pollution in the dining physical environment should be prohibited. Being exposed to this kind of physical environment for a long time will lead to children's cortical inhibition and affect the digestive gland secretion. The digestion and absorption have obstacles, influencing children's growth and development.

\section{B. Establish Health Records for children and assess children's nutritional status in time}

This record applies various means of medicine, nutrition, psychology, cooking and sociology. It is established based on characteristics of children's bodies and minds. It is of great significance. Whether children get a balanced nutrition or not, whether the growth and development needs are met or not need to be measured by various forms of indicators of growth and development needs eventually. The most important indicator is the height (It can be used to estimate physical development characteristics and to evaluate the growth rate), the weight (Regular weight increase is the good performance of children's health and nutritional status. If the rate of weight gain slows down, it means the dietary is incorrect. The energy and protein provided by food provided cannot meet children's needs of growth and development. It can also be caused by recurrent infections.), the head circumference (it represents the cranium size and development) and the chest circumference (it indicates the chest's volume and the developmental status of chest bones, chest muscles, back muscles and fat layers. To some extent, it indicates the development status of the body shape and respiratory organs). In China, children's physical development is often evaluated from the following three aspects: "HAZ", "WAZ" (referring to the due weight and height to a certain age), "WHZ" (referring to the due weight and to a certain height). If only HAZ is lower than normal value, it is called retardation. If only WHZ is lower than normal value, it is called emaciation. If both HAZ and WHZ are lower than normal values, it is severe chronic malnutrition. Otherwise, it is overweight and obesity.

\section{Correct bad dietary behaviors of children who are overweight or underweight starting with "compensatory education"}

As to children who are overweight, underweight, unhealthy, easy to get sick, who develop too fast or too slow and who have decreased visions, poor learning abilities, in addition to enhancing the cultivation education, teachers should also take active measures to make a detailed analysis of the reasons to carry out special treatments. Teachers should find the appropriate remedies, cooperating with parents so as to actively guide children to develop the habits of a balanced diet behaviorally and psychologically. As to children overweight, teachers can start from correcting the poor eating habits, commonly including irregular diets, eating too fast, eating too much, like sweets and fried foods. At the same time, teachers should also analyze children's psychological factors: children overweight have a higher sense of satiety than normal children. It's quite easy for them to feel hungry. Or they will show a good appetite when they feel nervous caused by excessive pressure; in addition to some disease factors (intestinal parasites, chronic diarrhea, food allergies etc.), children underweight also have bad eating habits. They are fastidious about food. They may have the partial eclipse or anorexia nervosa caused by psychological problems. Teachers should carry out specific treatments based on different situation: on one hand, starting from the diet constitutes, teachers can ask children overweight eat low-calorie foods (such as vegetables) as much as possible on the basis of a balanced diet, as to children underweight, teachers can ask them to eat high-calorie food appropriately. On the other hand, teachers should actively carry out psychological counseling to eliminate children's dining tension or psychology of picky, partial eclipse, anorexia, maximizing the intake of balanced nutrition.

\section{CONCLUSION}

As to the current implementation of dietary education in the kindergartens, it still needs to be understood, recognized, accepted and valued in the society. It also needs the social support and efforts. Thankfully, with the popularization of nutritionists' training in China, there will be a large number of nutritionists working in the kindergartens and schools in the near future. They will be entrusted with the task of dietary education and the glorious mission of implementing the children's dietary education together with teachers in the kindergartens and schools. Montessori once said: "If we want to introduce new ideas to improve people's customs and to inject new vitalities in the natural features, we have to consider children as the tool because adults are unable to complete this task. If we really want to spread the torch of civilization, we do need children's help to complete this mission... We can affect the social process by affecting our children." [6] 


\section{REFERENCES}

[1] Zuo Dongli. China Needs "Food Education" "Food Education” Needs Legislation, Chinese Food 2010, No. 13, Author: Zuo Dongli

[2] Li Lite. "Food Education" should be Education for All, Popular Science News, February 12, 2006
[3] Wang Ruiyuan (editor), Exercise Physiology, People's Education Press, 2002

[4] Lin Hongwei, Analysis on Chinese Food Cultural Connotation, Heilongjiang Science and Technology Information, 2009, No. 25

[5] Maria· Montessori. The Absorbent Mind, Gao Chao, Xue Jie (translators). Beijing: China Development Press 2006:53. 